IRA-International Journal of Management \& Social Sciences

ISSN 2455-2267; Vol.04, Issue 03 (2016)

Pg. no. 619-627

Institute of Research Advances

http://research-advances.org/index.php/RAJMSS

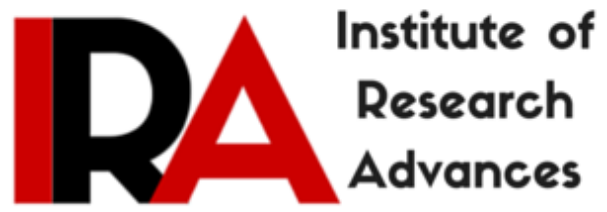

\title{
The 'Privacy Paradox' Investigation among the African American College Students: Privacy Concerns and Self-Disclosure on the Social Network Sites
}

Yanjun Yu, (Ph.D.)

Department of Computer Information Systems

Southern University at New Orleans, USA.

Type of Review: Peer Reviewed.

DOI: http://dx.doi.org/10.21013/jmss.v4.n3.p12

\section{How to cite this paper:}

Yu, Y. (2016). The 'Privacy Paradox' Investigation among the African American College Students: Privacy Concerns and Self-Disclosure on the Social Network Sites. IRAInternational Journal of Management \& Social Sciences (ISSN 2455-2267), 4(3), 619627. doi:http://dx.doi.org/10.21013/jmss.v4.n3.p12

(C) Institute of Research Advances

\section{(cc) EY-NO}

This work is licensed under a Creative Commons Attribution-Non Commercial 4.0 International License subject to proper citation to the publication source of the work.

Disclaimer: The scholarly papers as reviewed and published by the Institute of Research Advances (IRA) are the views and opinions of their respective authors and are not the views or opinions of the IRA. The IRA disclaims of any harm or loss caused due to the published content to any party. 


\begin{abstract}
This article examines the current status of privacy risk concern on Social Network Sites (SNS) among African American college students in a HBCU college in the United States. It also investigates the gender difference on this issue. The research focuses on the 'privacy paradox' phenomenon on SNS, in other words, how SNS users' privacy risk concern associates with their self-disclosure activity. The research findings are interesting and confirm the 'privacy paradox' phenomenon among the less studied African American college student community. The results show although the participants of the study fear something unpleasant can happen to them due to their presence on SNS and realize it is risky to publish their personal information on SNS, they still do some self-disclosure activities such as post photos and status. When they see the threat to their privacy due to their presence on SNS, they still post their status and videos on SNS. When they feel unsafe to publish their personal information on SNS, they still post photos and videos on SNS. Gender only significantly affect the post photo self-disclosure activity on SNS. The research contributes to the academia by investigating privacy concerns on the rarely studied minority community i.e., African American college student body. The study can provide tips for the privacy policy practitioners when they make or modify their privacy policies.
\end{abstract}

Keywords: Social Network Site (SNS), Privacy Paradox, Privacy risk, Privacy concern, Self-Disclosure, African American College Students, Gender.

\title{
Introduction
}

Social network site (SNS) was defined as web-based services that allow individuals to construct a public or semipublic profile within a bounded system, articulate a list of other users with whom they share a connection, and view and traverse their list of connections plus those made by others within the system (Boyd and Ellison, 2008, p. 211). The SNSs have been very popular among Internet users worldwide since the early $21^{\text {st }}$ century. Facebook, the dominate SNS in the world today, has over 1.71 billion monthly active users worldwide by July 2016 (Zephoria.com, 2016). The major motivations for people using SNS are finding friends and staying contact with their friends and family members effectively and efficiently. For example, a posted photo can be immediately notified to everyone on the person's friend list and help to keep friendships alive. The links and connections among individuals' friends can help them to build their social capital that might be crucial in the future (Ellison et al., 2007).

Despite those positive social benefits mentioned above, privacy threat concern has received SNS users and the general public's attention. User groups and online media such as major news sites continuously discuss privacy risks and suggest SNS users not revealing too much personal information on the SNS (Boyd, 2008). Although more and more SNS users are aware of the privacy risks, they still continuously post their information such as updated status, photos, and videos on the SNS sites. For example, Facebook reported 300 million photos are posted every day for July 2016 (Zephoria.com, 2016).

The disclosure of personal information despite existing privacy concerns is often called 'privacy paradox' (Jensen et al., 2005), which means individuals are indeed concerned about their privacy within the SNS, but don't apply these concerns to their usage behavior correspondingly (e.g., Acquisti \& Gross, 2006, Boyd \& Hargittai, 2010). The 'privacy paradox' has been partly explained by the extensions of the Social Exchange theory (e.g. Hui et al., 2006) and Privacy Calculus theory (Dinev and Hart, 2006). The users' attitude that "it won't happen to me" might explain some of the users' behavior (Dinev and Hu, 2007).

The present research tries to understand the dynamics behind self-disclosure on SNSs even though the users are aware of the privacy risks. Nevertheless, very little research has been done on examining the SNS issues among minority population such as African Americans, especially, the African American college students. The present study aims to investigate the "privacy paradox" phenomenon in the African American college student body. 


\section{Literature Review}

Self-Disclosure on the Social Network Sites

Self-disclosure on the social network sites (SNS) means providing personal information including "any message about the self that a person communicates to another" (Wheeless \& Grotz, 1976, p. 338). In general, self-disclosure is the beginning for any social relationship (Altman \& Taylor, 1973). In order to produce social ties, an individual needs to communicate with others the information about himself or herself. Self-disclosure can vary in scope; in degree of intimacy or depth and value, of sincerity or precision; in tone; and in the degree of awareness (Altman \& Taylor, 1973; Cozby, 1973). Self-disclosure is often the result of the consideration of risks and utility (Petronio, 2002). There is often tension between the self-disclosure and one's privacy protection, especially, in the virtual Internet world such as SNS.

On SNS, users provide personal identifiable information such as name, email address, relationship status, friends' circle along with their taste of music, books, and movies; some even disclose their addresses and phone numbers in their profiles. Furthermore, the SNS users can communicate with the other users by writing on their "wall", commenting or updating their status. For example, Facebook allows users to subscribe News Feed to observe their friends' updates right after those updates posted.

The theoretical foundations of self-disclosure are social exchange theory that states interpersonal relationships are based on a subjective evaluation of benefits and costs (Homans, 1958), and the privacy calculus theory that argues some users feel that the returns for disclosure offset the risk of their privacy being compromised (Culnan and Armstrong, 1999; Dinev and Hart, 2006). Therefore, privacy loss can be seen as the price of acquiring desired benefits (Hui et al., 2006). Although there are no systematical studies about the benefits of self-disclosure on SNSs, initial insights suggest that enjoyment (e.g., Rosen and Sherman, 2006), self-presentation (Boyd, 2007) and the ability to maintain social ties (Ellison et al., 2007) can contribute to user's self-disclosure.

\section{Privacy Risks on Social Network Sites}

The cost dimension of the privacy calculus equation on SNS has been denoted with perceived privacy risks and/or privacy concerns by empirical research. Both constructs are risk related and negatively affect user participation such as self-disclosure on SNS (e.g. Dinev and Hart, 2006). In E-commerce context, privacy risks typically refer to the collection and secondary use of information by service providers (Malhotra et al., 2004). On the other hand, in the SNS context, the privacy risks associate with the public accessibility of users' information i.e., secret sharing, collection and sharing of information by third parties, identity theft or use of the information for phishing (Hogben, 2007). Wieschowski (2007) pointed out that the intense media coverage combined with negative personal experience have inevitably influenced user perceptions of privacy threats. This awareness of privacy risks is most likely to diminish a user's willingness to share information on SNS.

However, previous research studies have found that although many Internet users express privacyprotectionist attitudes, which is rarely reflected to their actual behavior (Forrester Research, 2005; Jupiter Research, 2002; Metzger, 2006). For example, Spiekermann et al (2001) found there is very little evidence that privacy concerns were related to people's actual behavior in their experiment. Metzger (2006) discovered that people's privacy concerns and their disclosure don't associate with each other in an e-commerce site; in addition, the content of a privacy policy or presence of a privacy seal and users' disclosure behavior don't associate with each other, either. Furthermore, Krahsnova et al. (2010) proved that the rewards people gain i.e. convenience, relationship building and enjoyment from engaging in intensive communication on online social networks can overshadow the risks and induce them to reveal more information about themselves.

\section{African American College Students on Social Network Sites}

Byrne (2007) was one of the first studies of a Black SNS — BlackPLanet and examined the relationship between public discourse about community issues and civic participation. She reported the most popular 
online forums on BlackPlanet were about relationships (55\%), heritage and identity (9\%), religion and spirituality (6.6\%), current events (4.2\%), and women (3\%). However, none of these discussions was about privacy risks on SNS. Grasmuck et al. (2009) pointed out that Facebook is a potentially rich site for enhancing understanding of racial identity and display and little is known about African American online users. In their study, they examined the African American students' projected identity using visual cues about race through photographs and found African American students' Facebook profile projected a visual self was dramatically more social than non-African American students'. Martinez-Aleman and Wartman (2009) suggested that African American and Hispanic students more concerned with how they would be read by others on Facebook. As Grasmuck et al. (2009) pointed out that very little SNS research has focused on minority community so far such as the African American college students' usage of SNS, particularly their privacy risk concerns and self-disclosure behavior, as reviewed above.

\section{Gender}

In self-disclosure behavior on SNS research stream, gender, as an interesting factor, has been studied intensively. However, many research findings don't agree with each other. It is unclear whether gender difference exists in this type of research. For example, Parker \& Parrott (1995) found women were generally more willing to reveal personal information and more often than men. Especially, when they disclose the personal information to the known persons (Dindia \& Allen, 1992). For the social web context, Tufekci (2008) discovered gender differences in terms of self-disclosure in SNS profiles, and women are more cautious about to whom they grant access to their profile information (Fogel \& Nehmad, 2009). Moreover, Cho \& Hung (2011) found that women are more sensible about privacy issues than men. On the other hand, Barak and Gluck-Ofri (2007) explored only minor gender differences in discussion forums. Cho (2007) did not find any significant differences in self-disclosure between men and women in online chats.

As Grasmuck et al. (2009) pointed out that very little SNS research has focused on minority community so far such as the African American college students' usage of SNS, particularly their privacy risk concerns and self-disclosure behavior, as reviewed above. The present study tires to shed light on this less studied population, and the following research questions were formulated:

1. What is the current status of African American college students' privacy concern and selfdisclosure behavior on SNS? What is the association between their privacy concern and selfdisclosure behavior on SNS?

2. Do female and male African American college students behave differently in terms of selfdisclosure of themselves on SNS? If so, what is the difference?

\section{Research Method}

Sample Selection

A total of 131 African American students at one of the Historically Black College and University (HBCU) colleges in a Southern Urban city in the United States participated in this study by taking the survey operated by the author. Those students were from multiple sections of an entry level technology introduction course and had experience with Facebook. Participants were rewarded with extra credits. SPSS was used for data analysis.

To operate this research, the study relied on pre-tested scales of perceived privacy risk, and selfdeveloped items on self-disclosure. The items of perceived privacy risk are based on Malhotra et al. (2004) with 7 likert-scale ranged from strongly agree to strongly disagree. The self-developed items on selfdisclosure behavior focus on status update, post photos, and post videos on Facebook with the following 5 scale frequencies: 1 -very frequently (close to $100 \%$ of the time) to 5 -never. 
The sample consisted of 46 male (35\%) and 85 female (65\%) students; $90 \%$ of participates are African American; $87 \%$ of them are younger than 35 years of age with the range from younger than 20 to older than 60 .

\section{Results}

The primary purpose of the present study was to explore the current status of privacy risk concern among African American college students who use SNS. Findings from the survey are presented by answering the major research questions.

Research question 1: What is the current status of African American college students' privacy concern and self-disclosure behavior on SNS? What is the association between their privacy concern and selfdisclosure behavior on SNS?

When asked participants whether they fear something unpleasant can happen to them due to their presence on SNS, $6.1 \%$ of them strongly agreed, $16.8 \%$ of them picked agree, and $11.5 \%$ of them chose somewhat agree; in total $34.4 \%$ participants showed their privacy risk concern. When asked them whether they feel it is risky to publish their personal information on the SNS, 32.8\% of them strongly agreed, $19.1 \%$ of them said agree, and $10.7 \%$ of them chose somewhat agree; in total, $62.6 \%$ of them think it is risky to publish their personal info on the SNS. When asked them whether they see real threat to their privacy due to their presence on the SNS, $16.8 \%$ of them strongly agreed, $11.5 \%$ of them agreed, and $11.5 \%$ of them somewhat agreed; in total $39.7 \%$ agreed they see the real threat to their privacy due to their presence on the SNS. When asked them whether they feel unsafe publishing their personal information on the SNS, $29.8 \%$ of them strongly agreed, $15.3 \%$ of them agreed, and $12.2 \%$ of them somewhat agreed; in total $57.3 \%$ of them agreed that it is unsafe publishing their personal information on the SNS. The results are interesting: when the questions relate to their personal information publication on SNS, majority (more than 50\%) participants showed their privacy risk concern on SNS; but when the questions talk about their presence on SNS, the potential privacy risks are not so obvious to them, and only about $40 \%$ of them see it affects their privacy on SNS.

When investigating participants' self-disclosure activities on SNS for example, regarding post status activity, the author discovered that $16.8 \%$ of them post their status on SNS very frequently, $13.7 \%$ of them chose frequently, $28.2 \%$ picked somewhat frequently, in total $58.8 \%$ of them post their status on SNS some kind of frequently; regarding post photo activity, $22.1 \%$ of them post their photos very frequently, $18.3 \%$ of them did it frequently, and $28.2 \%$ of them did it somewhat frequently; in total, $68.7 \%$ of them post their photos on SNS some kind of frequently. Regarding post video activity, $10.7 \%$ of them post their videos very frequently, $9.9 \%$ of them did it frequently, $13 \%$ of them did it somewhat frequently; in total, 33.6\% of participants post their videos on SNS some kind of frequently. Among three selfdisclosure activities on SNS, post status and post photos are more popular than post videos. Majority (i.e. more than 50\%) of the participants disclose their personal information on SNS some kind of frequently. Less than $50 \%$ of them poste their personal video on SNS, and the possible explanation is that the video is still not as popular as photos and status, and will consume more space and need faster Internet speed to post them on SNS.

When we look at relationships among those constructs: the self-disclosure activities, PostStatus, PostPhoto, and PostVideo, positively correlate with each other significantly (see table 1); which indicates if the individual tends to post his/her status frequently on SNS, he/she will post photos and videos frequently as well, vice versa. PostStatus negatively correlates to UnSafeToPublish on SNS privacy concern significantly, which means if the individual feels it is unsafe to publish his/her personal information on SNS, he/she will post his/her status on SNS less frequently. PostPhoto negatively correlates to Threat privacy concern significantly, which means if the individual sees the real threat to his/her privacy due to his/her presence on SNS, he/she will post less photos on SNS. Threat and 
UnsafeToPublish positively correlate to each other significantly, which indicates if one sees the threat to his/her privacy on SNS, he/she also feels it is unsafe to publish his/her personal information on the SNS. Finally, PostPhoto negatively correlates to gender significantly, which shows male participants post significantly more photos on SNS than their female counterparts.

Table 1 Correlations

\begin{tabular}{|c|c|c|c|c|c|c|c|c|}
\hline & PostStatus & PostPhoto & PostVideo & $\begin{array}{l}\text { Fear } \\
\text { Unpleasant }\end{array}$ & $\begin{array}{l}\text { RiskyTo } \\
\text { Publish } \\
\end{array}$ & Threat & $\begin{array}{l}\text { Unsafe } \\
\text { ToPublish } \\
\end{array}$ & Gender \\
\hline PostStatus & 1 & $.402 * *$ & $.322 * *$ & .030 & -.111 & -.170 & $-.185^{*}$ & -.148 \\
\hline PostPhoto & $.402 * *$ & 1 & $.361 * *$ & -.036 & -.158 & $-306 * *$ & -.133 & $-.174 *$ \\
\hline PostVideo & $.322 * *$ & $.361 * *$ & 1 & .171 & -.014 & -.058 & -.135 & -.052 \\
\hline FearUnpleasant & .030 & -.036 & .171 & 1 & .166 & -.062 & -.065 & .043 \\
\hline RiskyToPublish & -.111 & -.158 & -.014 & .166 & 1 & .032 & .073 & -.035 \\
\hline Threat & -.170 & $-.306 * *$ & -.058 & -.062 & .032 & 1 & $.438 * *$ & .072 \\
\hline UnsafeToPublish & $-.185 *$ & -.133 & -.135 & -.065 & .073 & $.438 * *$ & 1 & .093 \\
\hline Gemder & -.148 & $-.174 *$ & -.052 & .043 & -.035 & .072 & .093 & 1 \\
\hline
\end{tabular}

**. Correlation is significant at the 0.01 level (2-tailed).

*. Correlation is significant at the 0.05 level (2-tailed).

Research question 2: Do male and female African American college students behave differently in terms of self-disclosure activities on SNS? If so, what is the difference?

As the previous analysis of the correlations among studied constructs show (see table 1), the only significant difference between male and female participants' perceived privacy risks concern and selfdisclosure activities is that male participants post significantly more photos on SNS than their female counterparts. The ANOVA result in table 2 proves the significant difference on the PostPhoto selfdisclosure activity between male and female participants $\left(F_{(1,129)}=4.029, p<0.05\right)$.

Table 2 ANOVA

\begin{tabular}{|ll|l|l|l|l|l|}
\hline & Sum of Squares & df & Mean Square & F & Sig. \\
\hline PostPhoto & Between Groups & 6.689 & 1 & 6.689 & 4.029 & 0.047 \\
& Within Groups & 214.151 & 129 & 1.660 & & \\
& Total & 220.840 & 130 & & & \\
\hline
\end{tabular}

Discussion

The data analysis shows that African American college students are active social network sites (i.e., Facebook in this study) users. They are aware of the privacy risks on SNS. However, the interesting findings are if they know their personal information are involved on SNS, majority of the participants do agree they feel the threat to their privacy and it is unsafe to publish their information on SNS; when the survey questions just mention their presence on SNS, majority of the participants don't see the privacy risk. 
Not every perceived privacy risk construct significantly correlates to the participant's self-disclosure activities on SNS. As we discussed previously, PostStatus negatively correlates to UnSafeToPublish on SNS privacy concern significantly, and PostPhoto negatively correlates to Threat privacy concern significantly. These results partially correspond to the 'privacy paradox'. Although the African American SNS users fear something unpleasant can happen to them due to their presence on SNS and realize it is risky to publish their personal information on SNS, they still do some self-disclosure activities such as post photos and status. When they see the threat to their privacy due to their presence on SNS, they still post their status and videos on SNS. When they feel unsafe to publish their personal information on SNS, they still post photos and videos on SNS.

Gender only affect the post photo disclosure activity on SNS. Surprisingly, African American male college students intend post more photos on SNS than their female counterparts.

\section{Contributions}

This study contributes to the scholar field by investigating the privacy risk topic on SNS among the rarely researched population i.e. African American college students. The research results support the 'privacy paradox' phenomenon on SNS and proves that the privacy concern doesn't completely reflect to individuals' action in the African American college student body. For practitioners, when the social network sites privacy policy makers make or modify their privacy policies for the targeted minority community, they need to do it more strategically.

\section{Limitations}

The study has a relatively small sample size, which can affect the data analysis results. Author plans to collect more data on this topic in the future, which may provide detailed insights on the investigated topics. Another limitation is that the survey results collected are based on students' self-report. Although college students are the major users of the SNS such as Facebook, they may not represent the whole SNS user population. The author plans to collect more data from the real user pool of SNS sties in the future.

\section{Conclusion}

This study explores the privacy concern status of African American college student users of the social network sites such as Facebook. It also investigates gender differences on self-disclosure activities among African American college students. The findings of the study are interesting and provide insights for researchers in the SNS' privacy risks field and practitioners of privacy policy makers involving in SNS.

\section{References}

Acquisti, A., \& Gross, R. (2006, June). Awareness, information sharing, and privacy on the Facebook, Paper presented at the $6^{\text {th }}$ "Privacy Enhancing Technologies" workshop Cambridge, England.

Altman, I., \& Taylor, D. A. (1973). Social penetration: The development of interpersonal relationships. New York: Holt, Rinehart, \&Winston.

Barak, A., \& Gluck-Ofri, O. (2007). Degree and reciprocity of self-disclosure in online forums. CyberPsychology \& Behavior, 10(3), 407-417.

Boyd, D. (2007). Why Youth (Heart) Social Networks Sites: The Role of Networked Publics in Teenage Social Life, in D. Buckingham (ed.) Youth, Identity, and Digital Media, Cambridge: MIT Press, PP. 119-142.

Boyd, D. (2008) Facebook's Privacy Trainwreck: Exposure. Invasion. and Social Convergence, Convergence: The International Journal of Research into New Media Technologies, 14, 1, 13-20. 
Boyd, D. M. \& Ellison, N. B. (2008). Social network sites: Definition, history, and scholarship, Journal of Computer-Mediated Communication, 13(1), 210-230.

Boyd, D., \& Hargittai, E. (2010). Facebook privacy settings: Who cares? First Monday, 15(8). http://www.uic.edu/htbin/cgiwrap/bin/ojs/index.php/fm/article/view/3086/2589 (June 6th, 2011).

Cho, S. H. (2007). Effects of motivations and gender on adolescents' self-disclosure in online chatting. CyberPsychology \& Behavior, 10(3), 339-345.

Cho, V., \& Hung, H. (2011). The effectiveness of Short Message Service for communication with concerns of privacy protection and conflict avoidance. Journal of Computer-Mediated Communication, 16(2), 250-270.

Cozby, P. C. (1973). Self-disclosure: A literature review. Psychological Bulletin, 79(2), 73-91.

Culnan, M. J. and Armstrong, P. (1999). Information Privacy Concerns, Procedural Fairness, and Impersonal Trust: an Empirical Investigation, Organization Science, 10(1), 104.

Dindia, K., \& Allen, M. (1992). Sex differences in self disclosure: A meta-analysis. Psychological Bulletin, 112(1), 106-124.

Dinev, T. and Hart, P. (2006) An Extended Privacy Calculus Model for E-Commerce Transactions, Information Systems Research, 17, 1, 61-80.

Dinev, T., and Hu, Q. (2007). The centrality of awareness in the formation of user behavioral intention toward protective information technologies, Journal of the AIS, 8, 7, 386-408.

Ellison, N. B., Steinfield, C. and Lampe, C. (2007) The benefits of Facebook "friends:" Social capital and college students' use of online social network sites, Journal of Computer-Mediated Communication, 12, 4, article 1.

$\begin{array}{llll}\text { Forrester } & \text { Research } & \text { (2005). } & \text { Available }\end{array}$ http://www.forrester.com/Research/Document/Excerpt/0,7211,38299,00.html.

Fogel, J., \& Nehmad, E. (2009). Internet social network communities: Risk taking, trust, and privacy concerns. Computers in Human Behavior, 25(1), 153-160.

Jupiter Research (2002). Seventy percent of US consumers worry about online privacy, but few take protective action, 2002. http://www.jmm.com/xp/jmm/press/2002/pr_060302.xml

Hogben, G. (2007). Security Issues and Recommendations for Online Social Networks, ENISA Position Paper No. 1

Homans, G. G. (1958). Social Behavior as Exchange, American Journal of Sociology, 63, 597-606.

Hui, K-L., Tan, B. C. Y. and Goh, C.Y. (2006) Online Information Disclosure: Motivators and Measurements, ACM Transactions on Internet Technology, 6, 4, 415-441.

Jensen, C., Potts, C. and Jensen, C. (2005) Privacy Practices of Internet Users: Self-reports versus observed behavior, International Journal Human-Computer Studies, 63, 1-2, 203-227. 
Krasnova, H., Spiekermann, S., Koroleva, K., and Hildebrand, T. (2010). Online Social Networks: Why We Disclose, Journal of Information Technology, 25, 109-125.

Malhotra, N. K., Kim, S. S. and Agarwal, J. (2004). Internet Users' Information Privacy Concerns (IUIPC): The construct, the scale, and a causal model, Information systems Research 15(4), 336355.

Metzger, M.J. (2006). Effects of Site, Vendor, and Consumer Characteristics on Web Site Trust and Disclosure. Communication Research, 33, 155-179

Parker, R., \& Parrott, R. (1995). Patterns of self-disclosure across social support networks: Elderly, middle-aged, and young adults. The International Journal of Aging \& Human Development, 41, 281-297.

Petronio, S. (2002): Boundaries of privacy. Dialectics of disclosure. Albany, NY: SUNY Press.

Rosen, P. and Sherman, P. (2006). Hedonic Information Systems: Acceptance of Social Networking Websites, in Americas Conference on Information Systems (Acapulco, Mexico, 2006), Paper 162.

Spiekermann, S., Grossklags, J. and Berendt, B. (2001). E-privacy in 2nd generation ECommerce: privacy preferences versus actual behavior, in: Proceedings of the Third ACM Conference on Electronic Commerce, Association for Computing Machinery (ACM EC'01), 38-47. Tampa, Florida, US.

Tufekci, Z. (2008). Can you see me now? Audience and disclosure regulation in online social network sites. Bulletin of Science, Technology \& Society, 20-36.

Wheeless, L. R., \& Grotz, J. (1976). Conceptualization and measurement of reported self-disclosure. Human Communication Research, 2(4), 338-346.

Wieschowski, S. (2007). Studenten demonstrieren gegen das SchnuffelVZ.

Zephoria.com (2016), https://zephoria.com/top-15-valuable-facebook-statistics/ accessed on 09/11/2016. 